\title{
Etching mechanism of barium strontium titanate (BST) thin films in $\mathrm{CHF}_{3} / \mathrm{Ar}$ plasma
}

\author{
DAI LiPing*, WANG ShuYa, SHU Ping, ZHONG ZhiQin, WANG Gang \& ZHANG GuoJun \\ State Key Laboratory of Electronic Thin Films and Integrated Devices, University of Electronic Science and Technology of China, Chengdu \\ 610054, China
}

Received February 22, 2011; accepted April 8, 2011

\begin{abstract}
Reactive ion etching was used to etch barium strontium titanate thin films in a $\mathrm{CHF}_{3} / \mathrm{Ar}$ plasma. BST surfaces before and after etching were analyzed by X-ray photoelectron spectroscopy to investigate the reaction ion etching mechanism, and chemical reactions had occurred between the F plasma and the $\mathrm{Ba}, \mathrm{Sr}$ and $\mathrm{Ti}$ metal species. Fluorides of these metals were formed and remained on the surface during the etching process. Ti was almost completely removed because the $\mathrm{TiF}_{4}$ by-product is volatile. Minor quantities of Ti-F could still be detected by narrow scan X-ray photoelectron spectra, and Ti-F was thought to be present in the form of a metal-oxy-fluoride. These species were investigated from O1s spectra, and a fluoride-rich surface was formed during etching. $\mathrm{BaF}_{2}$ and $\mathrm{SrF}_{2}$ residues were difficult to remove because of their high boiling point. The etching rate was limited to $12.86 \mathrm{~nm} / \mathrm{min}$. $\mathrm{C}-\mathrm{F}$ polymers were not found on the surface, indicating that the removal of $\mathrm{BaF}_{2}$ and $\mathrm{SrF}_{2}$ was important for further etching. A 1-min Ar/15 plasma physical sputtering was carried out for every 4 min of surface etching, which effectively removed remaining surface residue. Sequential chemical reaction and sputtered etching is an effective etching method for barium strontium titanate films.
\end{abstract}

barium strontium titanate, reaction ion etching, X-ray photoelectron spectroscopy, plasma

Citation: Dai L P, Wang S Y, Shu P, et al. Etching mechanism of barium strontium titanate (BST) thin films in $\mathrm{CHF}_{3} / \mathrm{Ar}_{\mathrm{r}}$ plasma. Chinese Sci Bull, 2011, 56: 2267-2271, doi: 10.1007/s11434-011-4561-5

With the rapid development of electronics and information technology, there is a great demand for high $\mathrm{K}$ dielectric materials. An example is ferroelectric high-K materials [1-4] required for many microwave applications [5]. Ferroelectric thin films possessing high permittivity are of great interest for application to high-K dynamic random access memory (DRAM) cells. Barium strontium titanate (BST) thin film ferroelectric materials are promising as capacitor dielectric components in future high density DRAM devices, because of their high dielectric constant, low leakage current, low temperature coefficient in electrical processes, small dielectric loss and lack of fatigue/aging [6-8]. BST can potentially provide significant improvements in device performance; however, several problems need resolving to realize

*Corresponding author (email: dlp@uestc.edu.cn) highly integrated DRAMs involving BST thin films. To efficiently integrate BST thin films into Si-based circuitry, an etching process for micro-patterning technology must be developed. The etching mechanism includes two major processes: ion-assisted etching reaction; and sputtering process to remove the reaction by-products. Thus, identifying by-product compositions is important for optimizing etching processes. There are several reported studies on the etching of BST thin films using chlorine and fluorine-based plasma chemistry [9-17]. There are also several reports investigating the properties of $\mathrm{CF}_{4} / \mathrm{Ar}$ plasmas both experimentally and theoretically. Unfortunately, the etching mechanism of BST films is still not clear, perhaps because BST thin films are a relatively new material to the microelectronics technology. Thus, most work has focused on technological aspects, with etching mechanisms having received little attention. Investigating the BST thin film dry-etching mechanism 
is important for improving etching performance.

In the current study, reactive ion etching (RIE) was carried out on $\mathrm{BST}$ thin films using $\mathrm{CHF}_{3} / \mathrm{Ar}$ plasma. The etched surface was analyzed by X-ray photoelectron spectroscopy (XPS) to determine the composition and chemical states of all elements present. The relative atomic percentage of compositions was determined by narrow scan XPS spectra and sensitivity factors. We have further clarified the chemical reaction of BST films with F plasma, and measured the etching rate. From the etching mechanism we offer details of an optimized etching process.

\section{Materials and methods}

BST thin films were deposited on $\mathrm{Si}$ substrates by radio frequency magnetron sputtering. The target was a BST ceramic, radio frequency power was $100 \mathrm{~W}$, substrate temperature was $500^{\circ} \mathrm{C}$, and the chamber $\mathrm{O}_{2}$ and $\mathrm{Ar}$ pressure during deposition was $4 \mathrm{~Pa}$. Deposition was carried out for $3 \mathrm{~h}$, followed by annealing at $600^{\circ} \mathrm{C}$ for $30 \mathrm{~min}$. Two BST films were etched by RIE in a $\mathrm{CHF}_{3} / \mathrm{Ar}$ plasma for $4 \mathrm{~min}$. The first film was bare and the second carried a photoresist mask to allow the etching rate to be ascertained. The RIE power was $200 \mathrm{~W}, \mathrm{CHF}_{3} / \mathrm{Ar}$ flow rate was $50 / 10 \mathrm{sccm}$, and the pressure inside the reaction chamber held constant at $20 \times 10^{-3}$ Torr. The Ar plasma post bombardment treatment RIE power was $200 \mathrm{~W}$.

The etch rate of BST films was measured using a surface profiler (DEKTAK150). The surface chemical compositions of as-deposited and etched BST films were analyzed using a XSAM800 instrument under ultrahigh vacuum $\left(2 \times 10^{-7} \mathrm{~Pa}\right)$ conditions using XPS (VG ESCALAB220I-XL), with a monochromated $\mathrm{MgK} \alpha$ source $(\mathrm{h} v=1253.6 \mathrm{eV})$. Scans for the elements $\mathrm{Ba}, \mathrm{Sr}, \mathrm{Ti}, \mathrm{O}$ and $\mathrm{F}$ used an X-ray beam with a $\sim 1 \mathrm{~mm}$ diameter. All samples were scanned after $30 \mathrm{~s}$ of sputtering to remove contamination effects from the film surface before XPS analysis.

\section{Results and discussion}

Figure 1 shows a typical XPS surface survey scan of a BST thin film after RIE in $\mathrm{CHF}_{3} / \mathrm{Ar}$ plasma, at $20 \times 10^{-3}$ Torr chamber pressure. $\mathrm{Ba}, \mathrm{Sr}, \mathrm{Ti}, \mathrm{O}$ and $\mathrm{F}$ were detected in the film surface after etching, and elemental $\mathrm{C}$ was also present. The $\mathrm{C}_{1 \mathrm{~s}}$ peak centered at $\sim 284.8 \mathrm{eV}$ was attributed to $\mathrm{C}-\mathrm{C} / \mathrm{C}-\mathrm{H}$ bonding. No high energy shoulder peaks of $\mathrm{C}_{1 \mathrm{~s}}-\mathrm{F}$ were observed which is supported by $\mathrm{F}_{1 \mathrm{~s}}$ spectra presented later in this report. $\mathrm{C}-\mathrm{C} / \mathrm{C}-\mathrm{H}$ was thought to originate from instrumental contamination. During the etching process, $\mathrm{C}$ plasma may have reacted with $\mathrm{O}$ to produce $\mathrm{CO}_{2}$ which desorbed from the BST surface. Compared with that of BST thin films specimens before etching, an increase of the $F_{1 s}$ peak was observed in the wide scan spectra of the etched

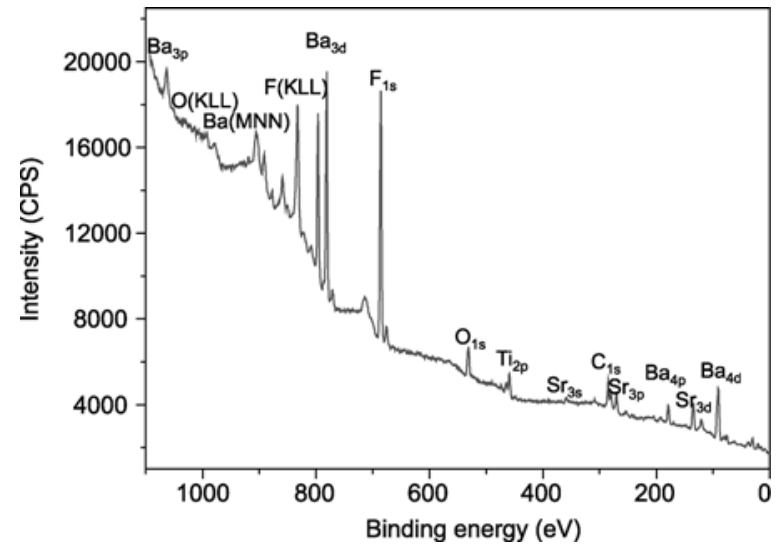

Figure 1 XPS wide scan spectra of a BST film after etching.

film. This indicated that fluorine-containing products accumulated on the etched surface.

XPS narrow scan spectra were recorded to determine the surface composition and chemical states of BST films before and after etching, and spectra for the $\mathrm{Ba}_{3 \mathrm{~d}}, \mathrm{Sr}_{3 \mathrm{~d}}, \mathrm{Ti}_{2 \mathrm{p}}$, $\mathrm{O}_{1 \mathrm{~s}}$ and $\mathrm{F}_{1 \mathrm{~s}}$ spectral regions are shown in Figure 2. From these spectra, the chemical reactions occurring between the $\mathrm{CHF}_{3}$ plasma and $\mathrm{Ba}, \mathrm{Sr}, \mathrm{Ti}$ and $\mathrm{O}$ elements were investigated. The Ar plasma acted solely as physical bombardment. The variations in $\mathrm{Ba}_{3 \mathrm{~d}}, \mathrm{Sr}_{3 \mathrm{~d}}, \mathrm{Ti}_{2 \mathrm{p}}, \mathrm{O}_{1 \mathrm{~s}}$ and $\mathrm{F}_{1 \mathrm{~s}}$ XPS peaks are apparent in Figure 2. In Figure 2(a), the $\mathrm{Ba}_{3 \mathrm{~d} 3 / 2}$ peaks at 796.14 and $794.34 \mathrm{eV}$ binding energy can be resolved into $\mathrm{Ba}-\mathrm{O}$ and $\mathrm{Ba}-\mathrm{F}$ components, respectively. $\mathrm{Ba}_{3 \mathrm{~d} 5 / 2}$ peaks at 781.07 and $778.88 \mathrm{eV}$ binding energy could also be resolved into to $\mathrm{Ba}-\mathrm{F}$ and $\mathrm{Ba}-\mathrm{O}$ components, respectively. The predominant $\mathrm{Ba}_{3 \mathrm{~d}}$ peaks of etched $\mathrm{BST}$ shifted towards higher binding energy by about 1.80 and $2.19 \mathrm{eV}$, upon $\mathrm{Ba}-\mathrm{O}$ bond being broken and reacted with the $\mathrm{F}$ plasma to form $\mathrm{Ba}-\mathrm{F}$. Figure 2(b) shows that the $\mathrm{Sr}_{3 \mathrm{~d}}$ spectral region could be resolved into $\mathrm{Sr}-\mathrm{F}$ and $\mathrm{Sr}-\mathrm{O}$ components. Peaks at 135.96 and $134.41 \mathrm{eV}$ binding energy corresponded to $\mathrm{Sr}_{3 \mathrm{~d} 3 / 2}$ and $\mathrm{Sr}_{3 \mathrm{~d} 5 / 2}$ of $\mathrm{Sr}-\mathrm{F}$, respectively, and peaks of $\mathrm{Sr}_{3 \mathrm{~d} 3 / 2}-\mathrm{O}$ and $\mathrm{Sr}_{3 \mathrm{~d} 5 / 2}-\mathrm{O}$ were observed at 134.62 and 133.09 $\mathrm{eV}$, respectively. Compared with the spectral line of as-deposited BST, that of the etched BST showed a high energy shift of about $1.52 \mathrm{eV}$ upon forming $\mathrm{Sr}-\mathrm{F}$ bonds. As shown in Figure 2(c), $\mathrm{Ti}_{2 \mathrm{p}}$ spectra could also be resolved into $\mathrm{Ti}-\mathrm{F}$ and $\mathrm{Ti}-\mathrm{O}$ components. Peaks at 464.60 and $458.87 \mathrm{eV}$ binding energy corresponded to $\mathrm{Ti}_{2 \mathrm{p} 1 / 2}$ and $\mathrm{Ti}_{2 \mathrm{p} 3 / 2}$ of $\mathrm{Ti}-\mathrm{F}$, respectively, and peaks at 463.57 and $457.84 \mathrm{eV}$ binding energy corresponded to $\mathrm{Ti}_{2 \mathrm{p} 1 / 2}-\mathrm{O}$ and $\mathrm{Ti}_{2 \mathrm{p} 3 / 2}-\mathrm{O}$, respectively. This indicated that the fluoride of $\mathrm{Ti}$ species was still present as a surface residue despite its high volatility. The Ti-F peak intensity became very weak and reflected a sharply decreasing $\mathrm{Ti}$ content. Figure 2(d) shows the $\mathrm{O}_{1 \mathrm{~s}}$ spectral region, which shows the superposition of peaks from oxides of $\mathrm{Ba}, \mathrm{Sr}$ and $\mathrm{Ti}$. The $\mathrm{O}_{1 \mathrm{~s}}$ peak at $\sim 529.45 \mathrm{eV}$ before etching shifted to $\sim 531.73 \mathrm{eV}$ following etching, 
representing a binding energy shift about $\sim 2.28 \mathrm{eV}$. Such chemical shift behavior may be influenced by two factors: the variation in oxide $(\mathrm{Ba}-\mathrm{O}, \mathrm{Sr}-\mathrm{O}$ and $\mathrm{Ti}-\mathrm{O})$ relative percentages through the chemical reaction; and $\mathrm{M}-\mathrm{O}-\mathrm{F}$ being formed. Upon the incorporation of fluorine and its replacement of oxygen, $\mathrm{M}-\mathrm{O}-\mathrm{F}$ was formed and oxygen electrons became more tightly bound, thus having a higher binding energy than those of metal oxides. It is not surprising that Ti-F was still detected in the film despite its high volatility, because it existed in the form of Ti-F-O. The intensity of $\mathrm{O}_{1 \mathrm{~s}}$ peak decreased significantly and reflected the decreasing $\mathrm{O}$ element percentage during the etching process. Figure 2(e) shows the $F_{1 \mathrm{~s}}$ spectral region, and the peak at $694.62 \mathrm{eV}$ binding energy corresponded to $\mathrm{F}_{1 \mathrm{~s}}-\mathrm{C}$ species of $\mathrm{CHF}_{3}$. The peak at $685.56 \mathrm{eV}$ binding energy represented the superposition of those from $\mathrm{F}_{1 \mathrm{~s}}-\mathrm{Ba}, \mathrm{F}_{1 \mathrm{~s}}-\mathrm{Sr}$ and $\mathrm{F}_{1 \mathrm{~s}}-\mathrm{Ti}$ species. No high energy shoulder peaks at 686.21-689.08 eV were apparent, indicating that no polymer containing $\mathrm{C}-\mathrm{F}$ remained
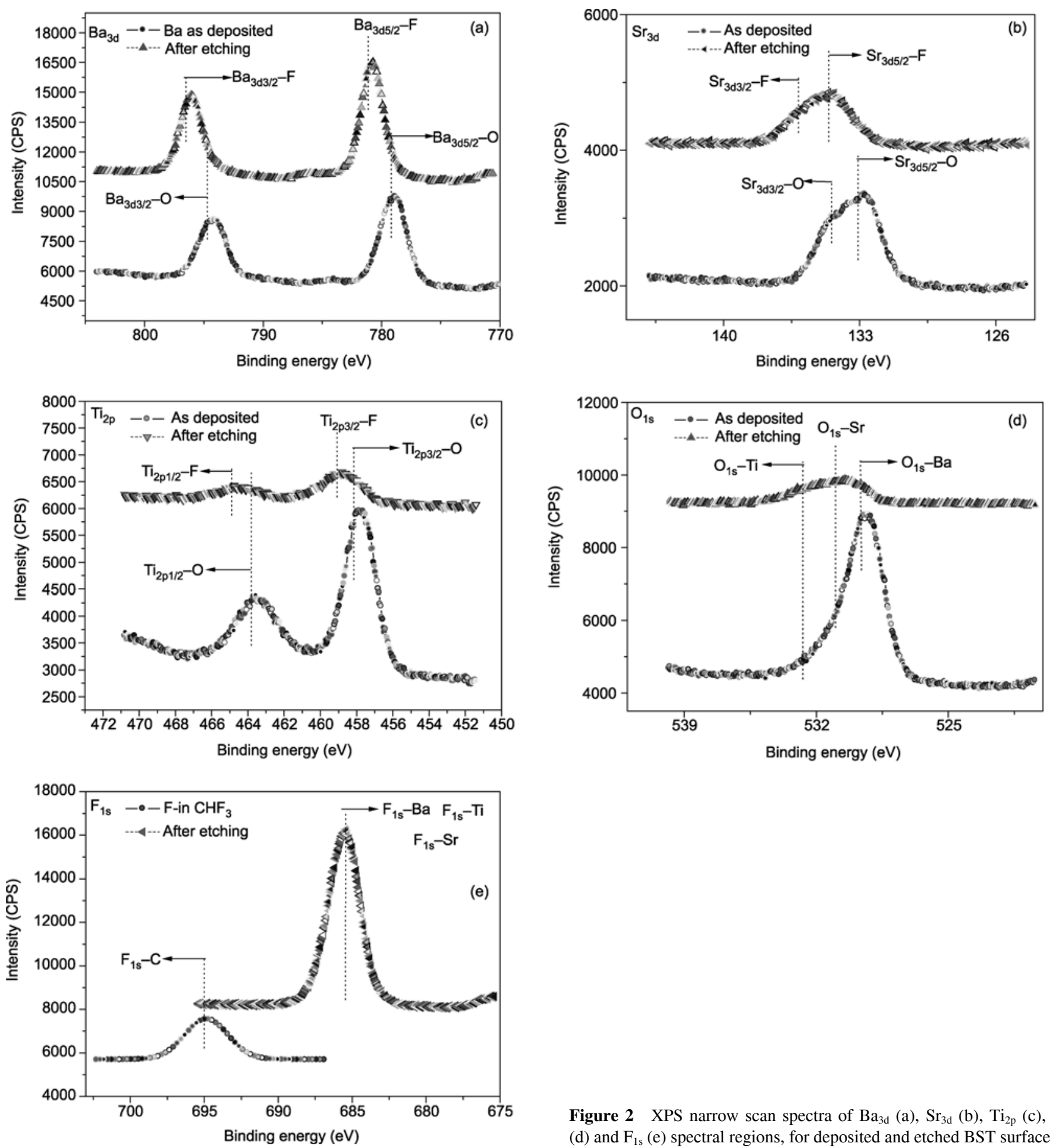

Figure 2 XPS narrow scan spectra of $\mathrm{Ba}_{3 \mathrm{~d}}(\mathrm{a}), \mathrm{Sr}_{3 \mathrm{~d}}(\mathrm{~b}), \mathrm{Ti}_{2 \mathrm{p}}(\mathrm{c}), \mathrm{O}_{1 \mathrm{~s}}$ (d) and $\mathrm{F}_{1 \mathrm{~s}}$ (e) spectral regions, for deposited and etched BST surfaces. 
on the BST film surface. From the above XPS analysis, the chemical reactions during etching can be summarized as follows: $\mathrm{Ba}-\mathrm{O}, \mathrm{Sr}-\mathrm{O}$ and $\mathrm{Ti}-\mathrm{O}$ bonds were broken during $\mathrm{CHF}_{3} / \mathrm{Ar}$ plasma bombardment, and $\mathrm{Ba}, \mathrm{Sr}$ and $\mathrm{Ti}$ atoms reacted with the $\mathrm{F}$ plasma to form fluorine-containing products, some of which were removed from the surface while other less volatile species remained. The $\mathrm{C}-\mathrm{F}$ bond was also broken and $\mathrm{C}$ plasma then reacted with $\mathrm{O}$ to produce $\mathrm{CO}_{2}$, which was volatile and desorbed from the surface. The $\mathrm{C}-\mathrm{H}$ bonds are thought to have also been broken, with the $\mathrm{H}$ plasma then reacting with $\mathrm{O}$ or $\mathrm{F}$ to produce volatile $\mathrm{H}_{2} \mathrm{O}$ or HF.

There were three components $\left(\mathrm{BaO}, \mathrm{SrO}, \mathrm{TiO}_{2}\right)$ in the BST film suspension, thus it is interesting to compare the relative compositions of as-deposited and etched BST surfaces. To investigate the role of $\mathrm{CHF}_{3} / \mathrm{Ar}$ plasma and to further study the etching mechanism, the relative atomic percentages of the as-deposited and etched surfaces were calculated from integrated XPS narrow scan peak intensities, and are shown in Table 1. While the XPS compositions measured in this work do not necessarily represent the true compositions, the relative changes induced by ion bombardment should be accurate and provide clues about relevant surface reactions. The relative atomic percentage of $\mathrm{F}$ in the BST after etching was high $(71.34 \%)$ which indicated that a fluoride-rich surface was formed during etching. Thus, chemical reactions occurred between the metal oxides and $\mathrm{F}$ plasma. Ba-O, Sr-O and Ti-O reacted to form $\mathrm{Ba}-\mathrm{F}, \mathrm{Sr}-\mathrm{F}$ and $\mathrm{Ti}-\mathrm{F}$, respectively, and the relative $\mathrm{O}$ atomic percentage significantly decreased. The $\mathrm{Ti}$ atomic percentage significantly decreased because volatile $\mathrm{TiF}_{4}$ (bp $284^{\circ} \mathrm{C}$ ) was formed and could be easily removed from the BST surface. While some Ti-F was still detected in the narrow scan spectra, it was likely to exist in the form of Ti-O-F. The atomic percentages of $\mathrm{Ba}$ and $\mathrm{Sr}$ showed minor decreases upon etching, because it was difficult to remove the $\mathrm{BaF}_{2}$ and $\mathrm{SrF}_{2}$ by-products with high boiling points of $2260^{\circ} \mathrm{C}$ and $2489^{\circ} \mathrm{C}$, respectively. The etch rate was calculated to be $12.86 \mathrm{~nm} / \mathrm{min}$, thus removal of $\mathrm{BaF}_{2}$ and $\mathrm{SrF}_{2}$ is important for further etching. Based on the above analysis, the RIE mechanism of BST in $\mathrm{CHF}_{3} / \mathrm{Ar}$ plasma has been elucidated. However, the need for approaches to remove $\mathrm{BaF}_{2}$ and $\mathrm{SrF}_{2}$ still remain. Physical sputtering is likely to be effective for their removal, given their very high boiling points. A 1-min

Table 1 BST surface elemental compositions for as-deposited and etched surfaces

\begin{tabular}{lccccc}
\hline \multicolumn{1}{c}{ Condition } & $\mathrm{Ba}(\%)$ & $\mathrm{Sr}(\%)$ & $\mathrm{Ti}(\%)$ & $\mathrm{O}(\%)$ & $\mathrm{F}(\%)$ \\
\hline As deposited & 8.44 & 9.16 & 24.99 & 57.41 & 0 \\
After etching & 6.02 & 5.72 & 4.19 & 12.72 & 71.34 \\
Ar post sputtering & 8.69 & 9.23 & 24.50 & 50.34 & 7.24 \\
\hline
\end{tabular}

Ar/15 plasma post bombardment treatment was carried out after every $4 \mathrm{~min}$ of surface etching. The relative atomic percentages of the post-treated surface are also shown in Table 1, and are similar to that of the as-deposited surface. This demonstrates that $\mathrm{BaF}_{2}$ and $\mathrm{SrF}_{2}$ remnants had been etched from the surface, and that Ar plasma post bombardment treatment is an effective supplement for the RIE of BST films.

\section{Conclusions}

BST thin films were etched in $\mathrm{CHF}_{3} / \mathrm{Ar}$ plasma using RIE. The elemental composition and chemical states of as-deposited and etched BST films were investigated by XPS to determine the etching mechanism. Etching led to the accumulation of fluorine-containing by-products on the BST surface, with Ti fluorides being easily removed. Fluorides of $\mathrm{Ba}$ and $\mathrm{Sr}$ remained on the surface as these residues were hard to remove. A 1-min Ar/15 plasma post bombardment treatment was carried out on the etched surface, and was shown to be effective for removing these residues. Sequential chemical reaction and sputter etching is an effective etching procedure for BST films.

This work was supported by the University of Electronic Science and Technology of China (Y02002010301045) and the Foundation of State Key Laboratory of Electronic Thin Films and Integrated Devices (kFJJ200909).

1 Gervais M, Gervais F, Champeaux C, et al. Strongly oriented BST films on $\mathrm{La}_{0.9} \mathrm{Sr}_{1.1} \mathrm{NiO}_{4}$ electrodes deposited on various substrates for integration of high capacitances on silicon. Appl Surf Sci, 2006, 252: 3085-3091

2 Gaillot D P, Zhao Q, Zhang F L, et al. Transparency cloak based on High- $\kappa$ BST rods. Proceedings of the 38th EuMC, 2008. 869-872

3 Noda $\mathrm{M}$, Inoue $\mathrm{K}$, Zhu $\mathrm{H}$, et al. Chopperless-operated dielectric bolometer mode of infrared image sensor with ferroelectric BST film using improved operation. IEEE I SAF, 2000, 2: 783-786

4 Belleville P, Bigarre J, Boy P, et al. Stable PZT sol for preparing reproducible high-permittivity perovskite-based thin films. J Sol-Gel Sci Techn, 2007, 43: 213-221

5 Ahamed F, Biggers R, Campbell A, et al. New research directions in tunable microwave dielectrics. Integr Ferroelectr, 2004, 66: 139-151

6 Challali F, Besland M P, Benzeggouta D, et al. Investigation of BST thin films deposited by RF magnetron sputtering in pure Argon. Thin Solid Films, 2010, 518: 4619-4622

$7 \mathrm{Hu}$ W C, Yang C R, Zhang W L, et al. Ferroelectric properties of $\mathrm{Ba}_{0.8} \mathrm{Sr}_{0.2} \mathrm{TiO}_{3}$ thin films prepared by $\mathrm{RF}$ magnetron sputtering. Integr Ferroelectr, 2006, 79: 131-138

8 Palathinkal T J, Cheng H F, Lee Y C, et al. Low loss tunable thick films based on $(\mathrm{Ba}, \mathrm{Sr}) \mathrm{TiO}_{3}$ and $\mathrm{Ba}_{4} \mathrm{Ti}_{13} \mathrm{O}_{30}$ materials. Integr Ferroelectr, 2004, 66: 213-221

9 Kim S B, Kim C-Il, Chang E G. Study on surface reaction of $\mathrm{Ba}, \mathrm{Sr}_{\mathrm{TiO}} \mathrm{T}_{3}$ thin films by high density plasma etching. J Vac Sci Technol A, 1999, 17: 2156-2161

10 Stafford L, Margot J, Langlois O. Barium-strontium-titanate etching characteristics in chlorinated discharges. J Vac Sci Technol A, 2003, 21: $1247-1252$

11 Kim S B, Lee Y H, Kim T H, et al. Etching mechanism of Ba,Sr.TiO films in high density $\mathrm{Cl}_{2} / \mathrm{BCl}_{3} / \mathrm{Ar}$ plasma. J Vac Sci Technol A, 2000, 
18: $1381-1384$

12 Choi S K, Kim D P, Kim C-II, et al. Damage in etching of Ba,Sr.TiO thin films using inductively coupled plasma. J Vac Sci Technol A, 2001, 19: 1063-1067

13 Kim G H, Kim K T, Kim C-II. Dry etching of Ba,Sr.TiO 3 thin films using an inductively coupled plasma. J Vac Sci Technol A, 2005, 23: 894-897

14 Zhang B, Quan Z C, Zhang T J, et al. Effect of oxygen gas and annealing treatment for magnetically enhanced reactive ion etched
$\left(\mathrm{Ba}_{0.65}, \mathrm{Sr}_{0.35}\right) \mathrm{TiO}_{3}$ thin films. J Appl Phys, 2007, 101: 014107(1-8)

15 Shibano T, Takenaga T, Nakamura K, et al. Etching of $\mathrm{Ba}, \mathrm{Sr}_{2} \mathrm{TiO}_{3}$ film by chlorine plasma. J Vac Sci Technol A, 2000, 18: 2080-2084

16 Wu D S, Lin C C, Horng R H, et al. Etching characteristics and plasma-induced damage of high-k $\mathrm{Ba}_{0.5} \mathrm{Sr}_{0.5} \mathrm{TiO}_{3}$ thin-film capacitors. J Vac Sci Technol B, 2001, 19: 2231-2236

17 Kang P S, Kim K T, Kim D P, et al. Study of damage reduction of $\mathrm{Ba}_{0.6}, \mathrm{Sr}_{0.4} \cdot \mathrm{TiO}_{3}$ thin films etched in $\mathrm{Ar} / \mathrm{CF}_{4}$ plasmas. J Vac Sci Technol A, 2003, 21: 1469-1474

Open Access This article is distributed under the terms of the Creative Commons Attribution License which permits any use, distribution, and reproduction in any medium, provided the original author(s) and source are credited. 